\title{
Assessment of Major Outcomes of Emergency Medical Services (EMS) in Relation to Signs and Symptoms at the Time of EMS call
}

\author{
Rajhans Prasad Anant, ${ }^{1}$ Kulkarni Priya Yogesh, ${ }^{2}$ Kelkar Dhananjay Shrikrishna, ${ }^{3}$ Jog Sameer Arvind, ${ }^{4}$ Ranade \\ Gouri, ${ }^{4}$ Utpat Sonal, ${ }^{5}$ Hande Varsha ${ }^{6}$
}

\section{Rajhans Prasad Anant, ${ }^{1}$ Kulkarni Priya Yogesh, ${ }^{2}$ Kelkar Dhananjay Shri- krishna, ${ }^{3}$ Jog Sameer Arvind ${ }^{4}$ Ranade Gouri, ${ }^{4}$ Utpat Sonal, ${ }^{5}$ Hande Var- sha ${ }^{6}$}

${ }^{1}$ FICCM,Chief Intensivist, Deenanath Mangeshkar Hospital and research centre, Pune, India.

${ }^{2}$ Associate Professor, Community Medicine, SMBT Medical College, Nasik. ${ }^{3}$ Medical director, Deenanath Mangeshkar Hospital and research centre, Pune, India.

${ }^{4}$ Consultant Intensivist, Deenanath Mangeshkar Hospital and research centre, Pune, India.

${ }^{5}$ Head of Emergency Department, Deenanath Mangeshkar Hospital and research centre, Pune, India. ${ }^{6}$ Senior emergency medical officer, Deenanath Mangeshkar Hospital and research centre, Pune, India.

\section{Correspondence \\ Dr Kulkarni Priya Yogesh \\ PIMS \& RC, Sangli. \\ Maharastra, India. \\ E-mail address: dr_pdkulkarni@yahoo. co.in}

\section{History \\ - Submission Date: 13-01-16 \\ - Revised Date: 14-09-16 \\ - Accepted Date: 18-11-16}

DOI : 10.5530/ijmedph.2017.1.2

Article Available online

http://www.ijmedph.org/v7/i1

\section{Copyright}

(C) 2017 Phcog.Net. This is an openaccess article distributed under the terms of the Creative Commons Attribution 4.0 International license.

\begin{abstract}
Background: EMS is in developing phase in India. There is a need to assess its outcomes based on signs and symptoms of patients at the time of EMS call. Aim: To assess the major outcomes of patients utilizing emergency medical services (EMS). Materials \& Methods: Study was designed to assess major outcomes among patients brought to the hospital by EMS in Pune. It was hospital record based study. A person with medical background was trained to extract required data as per proforma enlisting all the required information. Glass gow coma scale (GCS) was used to assess severity of the patients. Patients with incomplete records were excluded. Data were entered in Microsoft excel and imported in SPSS 15.0 software for analysis. Frequencies and proportions were enlisted. Associations were tested by Chi squared test. Results: 849 patients were enrolled. $39.75 \%$ were females, $61.0 \%$ were males. Mean age 62.56 years (+20.76). Ambulance services reached at scene within 25 minutes in $75 \%$ cases. Highest number (38.4\%) of patients had altered sensorium. $28 \%$ of the patients were in severe category and majority (62\%) were in mild to moderate category of GCS scale. 9.7\% patients with mild to moderate GCS died while $12.3 \%(27 / 212)$ patients with severe GCS died, difference in mortality was not significant $(p=0.220, O R=1.266,95 \%$ $\mathrm{Cl}=0.814-1.969)$. Highest percentage of deaths among severe GCS category were recorded in patients with road traffic accidents (VIII) and seizures (XI). Conclusion: Study re-emphasizes importance of to reduce mortality among patient with severe GCS to the extent of mild to moderate GCS. Different measures need to be installed in present EMS systems for Patients with RTA and seizures. Key Words: EMS, GCS, Mortality.
\end{abstract}

\section{INTRODUCTION}

EMS should be strengthened in India where medical emergencies and accidents are on rise. ${ }^{1}$ Growing population, increased life expectancy, changing age structure, urbanization, lifestyle changes are all the reasons behind it. ${ }^{2}$ To take care of growing medical emergencies, efforts are being made to expand Emergency medical services (EMS) and to make it easily accessible from all the levels. "Dial 108 service" in India, is a nationwide initiative to support emergency ambulance services ${ }^{1}$. It is based on the basic fundamental principle of EMS systems to have a common emergency communication number connected to responsive agencies. ${ }^{3}$ The effective transport component is also contributing to reduction in maternal and infant mortalities and will help to achieve various Millennium Development Goals. ${ }^{1}$

Prior to the government efforts, some private agencies started EMS services in Chennai, Mumbai, Pune etc. ${ }^{3}$ Deenanth Mangeshkar Hospital and Research centre (DMHRC), Pune, Maharashtra is one of the pioneering institution to set up EMS services in Maharashtra as early as in 1999 where the present study is carried out. ${ }^{4}$
'Golden hour' which typify the importance of Emergency Medical Services (EMS) all over the world., Patients who receive basic care from trained professionals and is transported to the nearest healthcare facility within 15-20 minutes of an emergency has the greatest chance of survival. It aids to control morbidity and prevent disability. ${ }^{5}$

Glasgow Coma Scale (GCS) is used by emergency physicians for rapid assessment, and to decide regarding further management of critical patient. ${ }^{7}$ It measures patient's best eye, motor and verbal responses. It is widely used and accepted prognostic indicator for both traumatic and non-traumatic patients. ${ }^{8}$ The score has been validated for its inter-observer reliability, which improves with training and experience in different scenarios. ${ }^{9}$ It is taken as index of how patient is critical ${ }^{10}$ and predictor of outcomes, mortality or disability as they are related to scores. ${ }^{11,12}$ It is also used a to evaluate response to ongoing treatment. Though, originally derived for head injury patients to describe level of consciousness, most emergency ambulance services use the GCS in their paramedic patient assessment. ${ }^{12}$
Cite this article : Rajhans PA, Kulkarni PY, Kelkar DS, Jog SA, Ranade G, Utpat S, Hande V. Assessment of major outcomes of emergency medical services (EMS) in relation to signs and symptoms at the time of EMS call. Int J Med. Public Health. 2017; 7(1):18-22 
Major outcomes of EMS patients in relation to their signs and symptoms made them to call EMS and their severity is studied in the present study. DMHRC has initiated its first ambulance service as early as in 1999 with its sister concern hospital. ${ }^{4}$ Intensivists from this hospital have their valuable contribution in the development of Maharashtra Emergency Medical Services (MEMS) which was launched in 2014 by government of Maharashtra, India. ${ }^{13}$ Institute is offering internship programme for PG -diploma EMS students. ${ }^{14}$ Till today, DMH has excellent network of EMS in the catchment area.

\section{MATERIAL \& METHODS}

It was a retrospective study based on hospital records. Study was carried out in Deenanth Mangeshkar Hospital and Research centre having its own emergency ambulance services. Ethical approval was sought from Institutional ethical committee.

Considering mortality as one of the major outcomes of EMS patients as $15 \%$ from previous studies, at 95\% confidence limit and allowable error as 5\%, the sample size was calculated using Epi Info Version 3.5.1. It came out to be 831 . Adding $5 \%$ non- response, the total number came out to be 849. Study subjects were patients who utilized EMS run by DMH during the year 2014 starting from $1^{\text {st }}$ January till we achieved desired sample size. Entries with incomplete data were excluded. Patients enrolled till we got desired sample size with complete data.

Proforma enlisting all the required information was developed for data collection. General information of the study subjects regarding demographic characteristics, emergency medical situation, patients' chief complaints, observations on general examination, GCS score, management during transportation and all the relavant information was gathered from ambulance call register and scanned copies of hospital records of ER sheets. Final outcome of patients was recorded from discharge summaries if patient was admitted to DMH itself and from transfer forms if shifted to other hospitals. Individual components of GCS score i. e. eye opening, verbal and motor responces were scored on EMS forms by ambulance personnels. They were summed up to get GCS score. Study subjects died at the scene, before or after arrival of ambulance and emergency team or with incomplete information to fill proforma were excluded from the study.

A person with medical background was trained to extract required data. Data were entered in Microsoft excel spreadsheet and imported in SPSS 15.0 software for analysis. Frequencies and proportions were enlisted. To test associations Chi squared test was used for qualitative variables.

\section{Definitions used}

EMS: Services that treat emergency medical conditions by rapid assessment, timely provision of appropriate interventions and promptly transport them to the nearest appropriate health facility by ambulance continuing monitoring/intervention/management. ${ }^{5}$

Scene: Place of the emergency situation.

Destination: Hospital or other treatment facility.

GCS: Calculated by summing up scores for eye, motor, verbal responses of the patients. Max GCS score as 15 represents good general condition. Categorized as <=8: Severe, 9-12: Moderate, >= 13: Mild.' ${ }^{15}$

\section{RESULTS}

We recruited total 849 patients who utilized EMS during the year 2014 fulfilling the inclusion criteria.

General characteristics and signs \& symptoms

$38.75 \%$ (329/849) were females, $61.25 \%$ (520/849) were males. Mean age 62.56 years $( \pm 20.76) .75 \%$ patients were above 55 years. $96.45 \%(819 / 849)$ emergencies were from Pune only, remaining were from various districts in Maharashtra. 3.42\% (29/849) were from low socio-economic status and made free of charge by the hospital.

$4.95 \%(42 / 849)$ were from rural area, $2.12 \%(18 / 849)$ were residing in urban slum, 92.93\% (789/849) were from urban area.

Signs and symptoms were categorized as shown in Table 1. Major signs and symptoms noted from patients were altered sensorium, severe breathlessness and severe chest pain/ palpitations and or sweating.

As per GCS, $28 \%$ of the patients were in severe category while majority $72 \%$ were in mild to moderate category of severity according to GCS scale (Figure 1). (Figure. 2) shows 49.67\% (152/306) patients with altered sensorium as a major chief complaint were in severe category of GCS score. It was significantly higher than among patients who were not having altered sensorium as a major chief complaint i.e. $13.25 \%(60 / 453)$.

\section{Major outcomes of EMS}

Highest proportion, $37.5 \%$, was shifted to ICU, DMH for further management (Figure 3). 13.55\% (115/849) study subjects died at the scene before/ after arriving EMS. They were excluded from further analysis.

\section{Death as one of the outcomes of EMS}

As shown in Figure 4, 9.7\% (53/547) critical patients with mild to moderate GCS died while $12.3 \%$ (27/212) critical patients with severe GCS died during the course of management. Difference was not statistically significant (Table 2, $\mathrm{p}=0.220$ ).

Significantly more deaths among severe category were observed in patients with signs and symptoms of category I $(\mathrm{p}=0.003)$, VIII $(\mathrm{p}=0.036)$, IX $(\mathrm{p}=0.049)$, XI $(\mathrm{p}=0.12)$.

\section{Arrival time at scene \& destination (Secondary outcome)}

In majority, $58.5 \%$ cases ambulance services reached at scene within 15 minutes, in $75 \%$ cases within 25 minutes of the call received. 59.4\% emergencies reached to destination within 30 minutes while $84.4 \%$ within 45 minutes. It took longer time to arrive at scene and destination as kilometers from scene to destination exceeded and obviously correlation was significant at 0.01 level (Spearman's rho $=0.366$ and 0.313 respectively).

\section{DISCUSSION}

In the present study, mortality among patients with severe GCS utilizing EMS was more than mortality among patients with mild-moderate GCS but the difference was not statistically significant ( $\mathrm{p}=.297)$. Mortality among patients with altered sensorium category of chief complaint which had significantly more patients (Table 1, category IV)) with severe GCS $(<=8)$ (Figure 2, category IV) is expected to be more than patients with other categories of chief complaints in absence of EMS as there exists a linear relationship between GCS score and the odds of mortality. ${ }^{16}$ But, highest percentage of deaths was noted in EMS patients with road traffic accidents (9\%, Figure 5, category VIII) and seizures (7\%, Figure 5, Categoty XI ) while mortality among EMS patients with altered sensorium was $4 \%$. Effective utilization of EMS in Golden Hour proved to be successful to decrease mortality especially among patients with altered sensorium subjects. It re-iterates importance of EMS to manage critical patients especially with severe GCS.

RTA is emerging epidemic in India. ${ }^{17}$ In present study, Highest percentage of deaths among severe category were recorded in patients with road traffic accidents (VIII) and seizures (XI) (Figure 5, 9\% and 7\% respectively). Globally, it is $8^{\text {th }}$ leading cause of mortality among young people (15-29 years). ${ }^{17} 44 / 849$ patients were in this age group, 15/44 were victims of RTA.

When one of the three components of GCS is not testable then a valid total cannot be calculated. Drug use, alcohol intoxication, shock or low 


\section{Table 1: Signs and symptoms of EMS patients}

\begin{tabular}{|cccc}
\hline $\begin{array}{c}\text { Signs and symptoms } \\
\text { Severe/ persistent chest pain and/ or } \\
\text { palpitations }\end{array}$ & I & Frequency & Percentage \\
$\begin{array}{c}\text { Breathlessness } \\
\text { Acute abdomen/ acute gastroenteritis }\end{array}$ & II & 143 & 16.8 \\
Altered sensorium & III & 220 & 25.9 \\
Weakness/ Paralysis of body part/ & IV & 94 & 11.1 \\
parts or whole body & V & 326 & 38.4 \\
Sudden severe headache & & 32 & 3.8 \\
New born with respiratory distress/ & VI & & \\
high grade fever & VII & 4 & 0.5 \\
Road Traffic accident & & 18 & 2.1 \\
High grade fever with or without rash & VIII & & 7.5 \\
Pre or postpartum haemorrhage & IX & 64 & 9.8 \\
Seizures & XI & 83 & 0.4 \\
Anuria/Retention of urine/UTI & XII & 3 & 6.5 \\
Severe Dyspnoea & XIII & 55 & 3.3 \\
Miscellaneous & XIV & 28 & 2.7 \\
\end{tabular}

${ }^{*}$ Some patients had multiple categories.

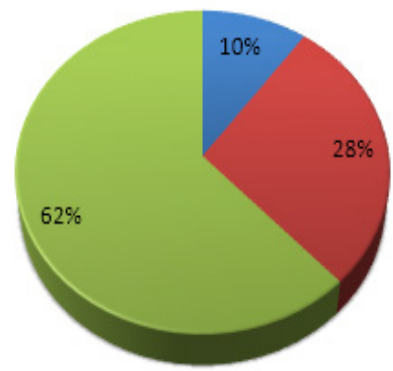

Figure 1: Severity of EMS patients according to Glassgow-coma scale

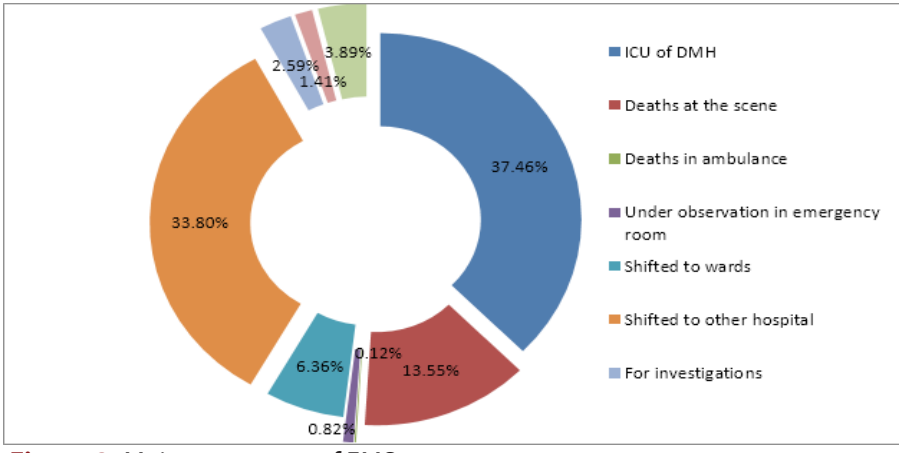

Figure 3: Major outcomes of EMS

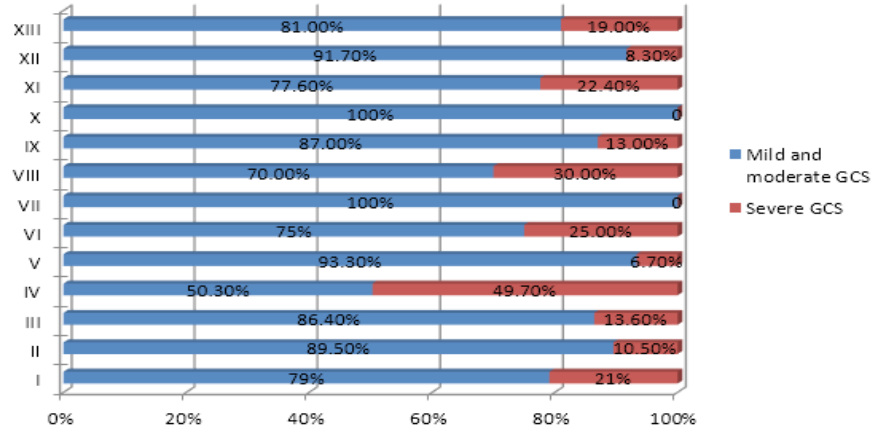

Figure 2: Percentage of severe \& mild / moderate GCS among categories of signs and symptoms (Categories according to Table 1)

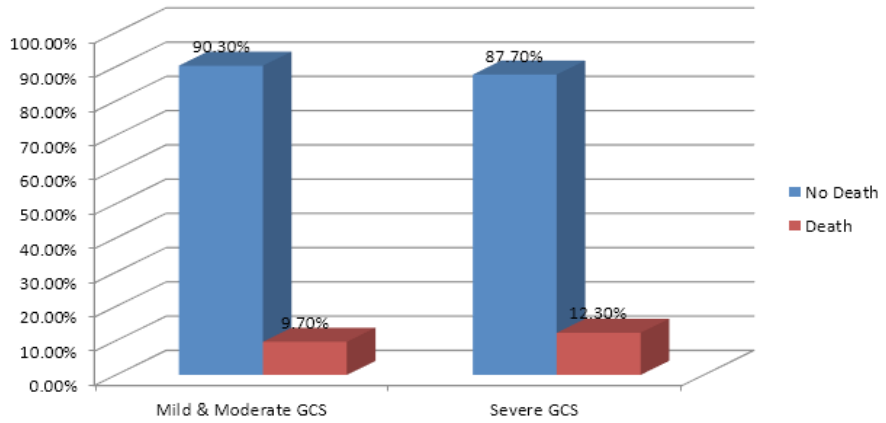

Figure 4: Percentage of Deaths as one of the outcomes of EMS

*deaths at scene before arrival of EMS excluded. ( $p=0.220, O R=1.266,95 \%$ $\mathrm{Cl}=0.814-1.969)$. 


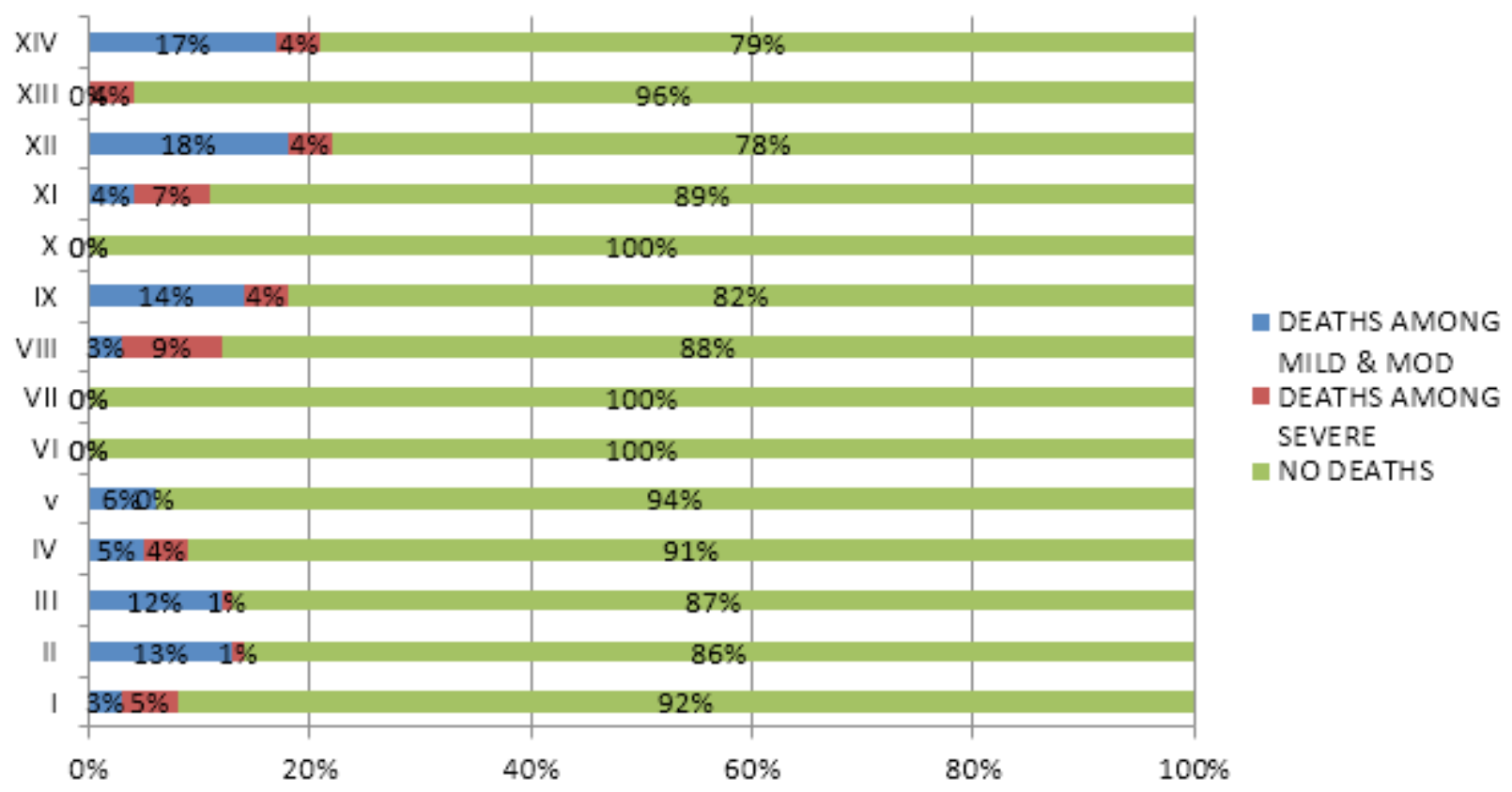

Figure 5: Deaths according to severity among different signs and symptoms

blood oxygen can alter patients' level of consciousness. ${ }^{18}$ Though, very few patients (3/849) were under the influence of alcohol or drug users, these factors can lead to inaccurate GCS score. Language, cultural and intellectual differences can interfere assessment of one or more component of the scale. ${ }^{21}$ It was minimized as our ambulance personals were from the same community and geographical area.

GCS helps to predict outcome of critically ill patients and to determine resource allocation for patients' management. ${ }^{20}$ But, there are huge variations in outcome of patients with same GCS score. Along with GCS other scales can also be utilized to assess emergency patients like APACHE (Acute physiology and chronic health evaluation) or NVPS (Nonverbal pain scale) for patients in whom verbal component of GCS can't be scored or wherever appropriate.

We tested whether mortality was associated with age $>=61$, gender, ruralurban or semiurban residence and presence of co-morbidities but these were insignificant ( $\mathrm{p}=0.305,0.322,0.211,0.167$ respectively). Presence of co-morbidities was also not associated with severe GCS ( $\mathrm{p}=0.436)$.

Overall, mortality among critical patients with severe GCS was $12.3 \%$ which was much lower than what previous studies of critically ill patients with severe GCS reported (19-65.3\%), ${ }^{20,22}$ but majority of these studies are restricted to traumatic brain injury patients.

In majority of the patients (75\%) EMS reached at scene within 25 minutes the call received. It took longer for patients residing places for from Pune. In our study time required to arrive at scene $\geq 25$ minutes was not associated with any mortality $(\mathrm{p}=0.337)$. Inspite of that, such calls can be re-directed to other EMS services and responsive agencies nearby the patient's place.

Thus, EMS of present hospital is working efficiently from timely reaching at the scene to managing the critical patient at the scene and during transportation.

\section{REFERENCES}

1. Das AK, Gupta SB, Joshi SR, Aggarwal P, Murmu LR, S Bhoi, T Sanson, et al., White Paper on Academic Emergency Medicine in India: INDO-US Joint Working Group. JAPI 2008;7;56:789-97.
2. Park K. Parks textbook of preventive \& social medicine. Chapter 5; epidemiology of communicable diseases, I. Respiratory infections: Tuberculosis. 22nd ed. P.166

3. A Xavier Raj. Saving lives through rural ambulance services: Experiences from Karnataka and Tamil Nadu states, India. Transport and Communications Bulletin for Asia and the Pacific. No. 84, 201452

4. Imron Subhan, Anunaya Jain. Emergency care in India: the building blocks. Int J Emerg Med. 2010;3(4):207-11. https://doi.org/10.1007/s12245-010-0223-7 ; PMid:21373285 PMCid:PMC3047870

5. Kobusingye OC, Hyder AA, Bishai D, Joshipura M, Hicks ER, et al. (2006) Emergency Medical Services. In: Jamison DT, et al., editor. Disease Control Priorities in Developing Countries. 2nd ed. New York and Oxford: Oxford University Press. PMCid:PMC3207517.

6. Potluri P. Emergency services in India. Available from: Asian Hospital \& Healthcare management, Hydrabad, India. Accessed on 3rd May 2016.

7. Gill M, Reilley DG, Green SM. Interrater reliability of Glasgow Coma Scale Scores in the Emergency Department. Ann Emerg Med. 2004; 43:215-23. https://doi.org/10.1016/S0196-0644(03)00814-X.

8. Glasgow coma scale. Jones C. Am J Nurs. 1979;79(9):1551-3. https://doi. org/10.2307/3424679 : https://doi.org/10.1097/00000446-197909000-00033 ; PMid:258560.

9. Interrater reliability of Glasgow Coma Scale scores in the emergency department. Gill MR, Reiley DG, Green SM. Ann Emerg Med. 2004;43(2):215-23. https://doi.org/10.1016/S0196-0644(03)00814-X.

10. Perel P, Arango M, Clayton T, Edwards P, Komolafe E, Poccock S, Roberts I, Shakur H, Steyerberg E, Yutthakasemsunt S. Predicting outcome after traumatic brain injury: practical prognostic models based on large cohort of international patients. MRC CRASH Trial Collaborators; BMJ. 2008;23;336(7641):425-9.

11. Green SM. Cheerio, Laddie! Bidding Farewell to the Glasgow Coma Scale. Annals of Emergency Medicine. 2011;30;58(5):427-30.

12. How to measure GCS. Available from: Emergency Medical Paramedic 2010;13.

13. Mane A. In the nick of time. The Indian Express. Pune News line; Monday July 172006.

14. Giving EMS its due recognition. Express healthcare management June 2006.

15. Lankova A. The Glasgow Coma Scale: clinical application in Emergency Departments. Emergency Nurse. 1;14(8):30-5

16. Ting HW, Chen MS, Hsieh YC, Chan CL. Good mortality prediction by Glasgow Coma Scale for neurosurgical patients. J Chin Med Assoc. 2010;73(3):139-43. https://doi.org/10.1016/S1726-4901(10)70028-9.

17. Ting HW, Chen MS, Hsieh YC, Chan CL. Good mortality prediction by Glasgow Coma Scale for neurosurgical patients.; J Chin Med Assoc. 2010;73(3):139-43. https://doi.org/10.1016/S1726-4901(10)70028-9.

18. Annadurai K, Mani G, Danasekarandian R. Recurring tragedy of road traffic accidents in India: Challenges and opportunities. J Crit Care Med. 2015 Jul; 19(7):434-5. https://doi.org/10.4103/0972-5229.160303. 
19. Nursing Practice Review. Forty years on: updating the Glasgow Coma Scale. Nursing Times 2014:110;42. Available from: www.nursingtimes.net; accessed on 3.5.2016.

20. Healey C, Osler TM, Rogers FB, Healey MA, Glance LG, Kilgo PD, Shackford SR, Meredith JW. Improving the Glasgow Coma Scale score: motor score alone is a better predictor. J Trauma. 2003;54(4):671-8;678-80.

21. Steven M. Green. Cheerio, Laddie! Bidding Farewell to the Glasgow Coma Scale. Annals of Emergency Medicine; November 2011, Volume 58;5:427-430. https://doi.org/10.1016/i.annemergmed.2011.06.009 ; PMid:21803447.

22. Nursing Practice Review. Forty years on: updating the Glasgow Coma Scale. Nursing Times. 2014:110;42 . Available from: www.nursingtimes.net; accessed on 3.5.2016.

23. Mclntyre A, Mehta S, Aubut J, Dijkers M, Teasell RW. Mortality among older adults after a traumatic brain injury: a meta-analysis.. Brain Inj. 2013;27(1):3140. https://doi.org/10.3109/02699052.2012.700086; PMid:23163240.

Cite this article : Rajhans PA, Kulkarni PY, Kelkar DS, Jog SA, Ranade G, Utpat S, Hande V. Assessment of major outcomes of emergency medical services (EMS) in relation to signs and symptoms at the time of EMS call. Int J Med. Public Health. 2017; 7(1):18-22 